\title{
The safety of marine navigation based on a game theory
}

\author{
J. Lisowski \\ Faculty of Electrical Engineering, Department of Ship Automation, \\ Gdynia Maritime University, Poland
}

\begin{abstract}
This paper introduces selected methods of a game theory for ship collision avoidance at sea. The application of game control algorithms to determine a ship's safe trajectory, whilst passing other encountered ships in good and restricted visibility at sea, is presented. Regarding the methods of comparison for the safe ship's control in a collision situation, multi-stage positional noncooperative and cooperative games and multi-step matrix non-cooperative and cooperative games have been introduced. The considerations have been illustrated with examples of computer simulations of the algorithms to determine the safety of the ship's trajectories in a navigational situation of restricted visibility in the Kattegat Strait.
\end{abstract}

Keywords: game theory, marine systems, safety analysis, risk, ship control, computer simulation.

\section{Introduction}

One of the major problems in maritime transport is to ensure the safety of navigation. In order to ensure the marine safety, the ships are obliged to comply with the International Regulations for Preventing Collisions at Sea (COLREGS). However, these rules refer only to two ships and under the conditions of good visibility.

For the situation of a restricted visibility the regulations only specify recommendations of a general nature and are not able to consider all the necessary conditions which determine the passing course.

Consequently, the actual process of a ship passing other objects very often occurs in conditions of uncertainty and conflict accompanied by an inadequate 
co-operation of the ships within COLREGS. It is, therefore, reasonable to investigate, develop and represent the methods of a ship safety handling using the rules of theory based on dynamic game $[1,2,8,11,16]$.

\section{Safe ship control process}

The process of handling a ship as a multidimensional dynamic object depends both on the accuracy of the details concerning the current navigational situation obtained from the Automatic Radar Plotting Aids (ARPA) anti-collision system and on the form of the process model used for the control synthesis.

The ARPA system ensures monitoring of at least $20 j$ encountered ships, determining their movement parameters (speed $V_{j}$, course $\psi_{j}$ ) and elements of approaching to own ship moving with speed $V$ and course $\psi$ (to satisfy $D_{\min }^{j}=D C P A_{j}$ (Distance of the Closest Point of Approach) and $T_{\min }^{j}=T C P A_{j}$ (Time to the Closest Point of Approach) and also assess the risk of collision $r_{j}$ (see Figure 1).

The model of the process consists both of the kinematics and the dynamics of the ship's movement, the disturbances, the strategies of the encountered ships and the quality control index of the own ship [3-6, 9, 14].

The diversity of possible models directly affects the synthesis of the ship's control algorithms which are afterwards affected by the ship's control device, directly linked to the ARPA system and consequently determines the effects of safe and optimal control.

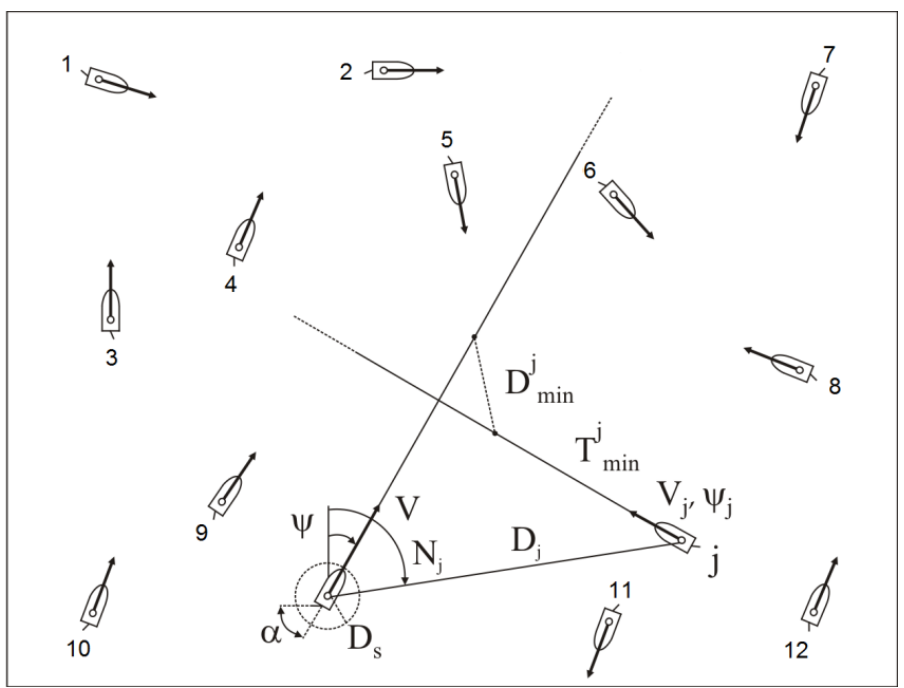

Figure 1: Navigational situation of ships passing - the own ship moving at $V$ speed and $\psi$ course with the $j$ ship met moving at $\mathrm{V}_{\mathrm{j}}$ speed and $\psi_{\mathrm{j}}$ course. 
Figure 2 shows a set of compromises of a ship safety control measured in terms of a collision risk and time-optimal strategy of the own ship control $[7,10]$.

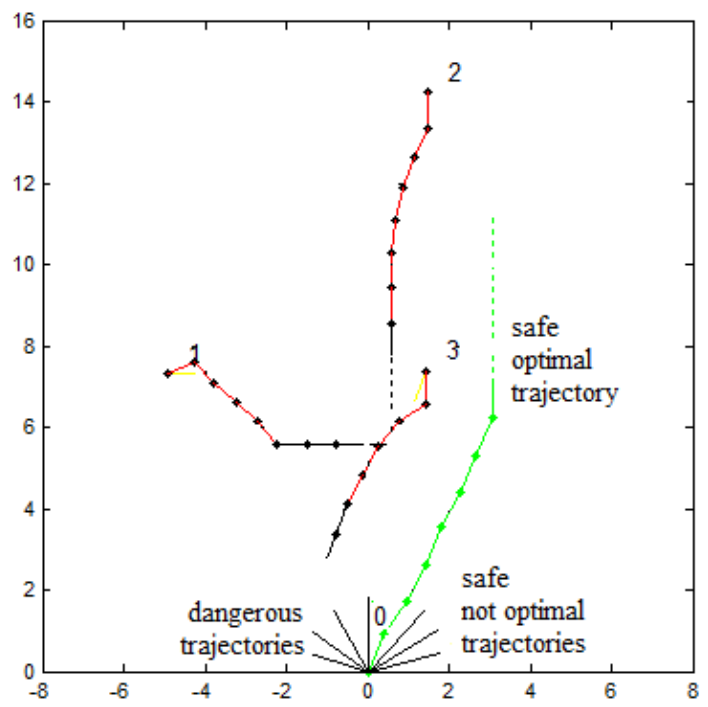

Figure 2: The possible trajectories in collision situation.

\section{Game models of a safe ship control}

The way of controlling a ship - which is a multi-dimensional and non-linear dynamic object - depends on the range and accuracy of information on the prevailing navigational situation and on the adopted model of the process (Figure 3).

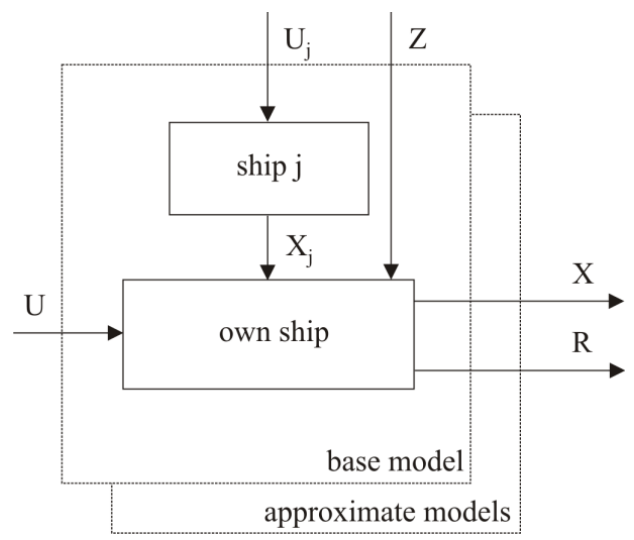

Figure 3: Block diagram of the models for safe control process. 
Figure 3 shows the block diagram of the possible models for safe control process, where: $U$ - vector of the own ship control, $U_{j}-$ control vector of the $j$ ship, $X_{j}$ - state vector of the $j$-th ship, $Z$ - disturbance vector, $X$ - state vector of the process, $R$ - vector of safety constraints.

The variety of the models to be adopted directly influences the synthesis of various algorithms supporting the navigator's work, and then on the effects of a safe control of the own ship's movement [12].

\subsection{Base differential game model}

The most general description of the own ship passing $j$ other encountered ships is the model of a differential game of $j$ moving control objects (see Figure 4).

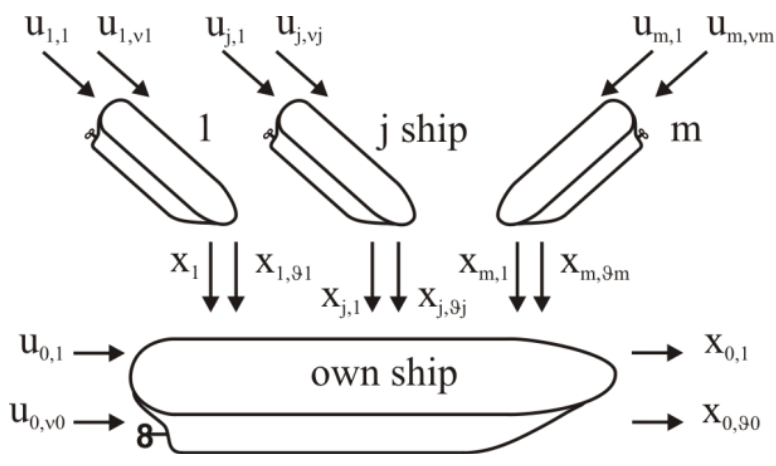

Figure 4: Block diagram of the basic model of differential game.

The properties of the process are described by the state equation:

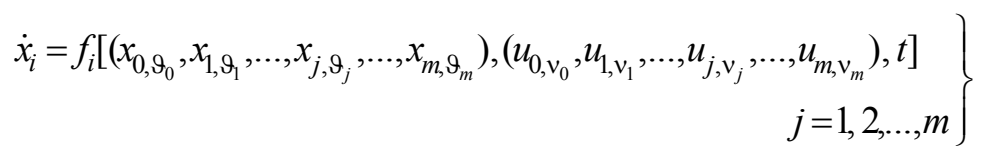

where:

$\vec{x}_{0, \vartheta_{0}}(t)-\vartheta_{0}-$ dimensional vector of the process state of the own ship determined in a time span $t \in\left[t_{0}, t_{k}\right]$;

$\vec{x}_{j, \vartheta_{j}}(t)-\vartheta_{j}-$ dimensional vector of the process state for the $j$-th met ship;

$\vec{u}_{0, v_{0}}(t)-v_{0}-$ dimensional control vector of the own ship;

$\vec{u}_{j, v_{j}}(t)-v_{j}-$ dimensional control vector of the $j$-th met ship. 
The constraints of the control and the state of the process are connected with the basic condition for the safe passing of the ships at a safe distance $D_{s}$ in compliance with COLREGS Rules, generally in the following form:

$$
g_{j}\left(x_{j, \vartheta_{j}}, u_{j, v_{j}}\right) \leq 0
$$

Goal function has form of the payments - the integral payment and the final one:

$$
I_{0, j}=\int_{t_{0}}^{t_{k}}\left[x_{0, \vartheta_{0}}(t)\right]^{2} d t+r_{j}\left(t_{k}\right)+d\left(t_{k}\right) \rightarrow \min
$$

The integral payment represents additional distance traveled by the own ship while passing the encountered ships and the final payment determines the final risk of collision $r_{j}\left(t_{k}\right)$ relative to the $j$ ship and the final deflection of the own ship $d\left(t_{k}\right)$ from the reference trajectory $[13,15,17]$.

\subsection{Approximate models}

For the practical synthesis of safe control algorithms various simplified models are formulated:

- triple linear programming model of non-cooperative multi-stage positional game,

- triple linear programming model of cooperative multi-stage positional game,

- dual linear programming model of non-cooperative multi-step matrix game,

- dual linear programming model of cooperative multi-step matrix game.

The degree of model simplification depends on an optimal control method applied and level of cooperation between ships (see Table 1).

Table 1: Algorithms of determining ship strategies.

\begin{tabular}{|c|c|c|c|}
\hline $\begin{array}{c}\text { Approximate } \\
\text { model }\end{array}$ & $\begin{array}{c}\text { Support } \\
\text { algorithm }\end{array}$ & $\begin{array}{c}\text { Method of } \\
\text { optimization }\end{array}$ & $\begin{array}{c}\text { Form of } \\
\text { decision }\end{array}$ \\
\hline $\begin{array}{c}\text { multi-stage } \\
\text { non cooperation } \\
\text { positional game }\end{array}$ & MNCPG & $\begin{array}{c}\text { triple linear } \\
\text { programming }\end{array}$ & $\begin{array}{c}\text { game } \\
\text { trajectory }\end{array}$ \\
\hline $\begin{array}{c}\text { multi-stage } \\
\text { cooperation } \\
\text { positional game }\end{array}$ & MCPG & $\begin{array}{c}\text { triple linear } \\
\text { programming }\end{array}$ & $\begin{array}{c}\text { game } \\
\text { trajectory }\end{array}$ \\
\hline $\begin{array}{c}\text { multi-step } \\
\text { non cooperation } \\
\text { matrix game }\end{array}$ & MNCMG & $\begin{array}{c}\text { dual linear } \\
\text { programming }\end{array}$ & $\begin{array}{c}\text { game } \\
\text { trajectory }\end{array}$ \\
\hline $\begin{array}{c}\text { multi-step } \\
\text { cooperation } \\
\text { matrix game }\end{array}$ & MCMG & $\begin{array}{c}\text { dual linear } \\
\text { programming }\end{array}$ & $\begin{array}{c}\text { game } \\
\text { trajectory }\end{array}$ \\
\hline
\end{tabular}




\section{Computer support algorithms}

In practice, methods of selecting a manoeuvre assume a form of approximate control algorithms supporting navigator decision in a collision situation. Algorithms are programmed in the memory of a Programmable Logic Controller PLC. This generates an option within the ARPA anti-collision system or a training simulator (see Figure 5).

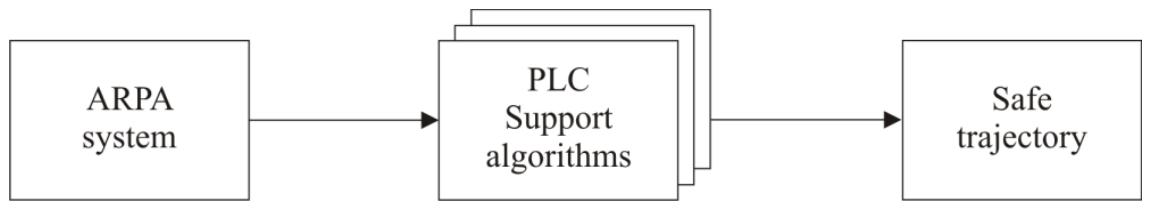

Figure 5: The structure of computer support system of navigator decision.

\subsection{MNCPG algorithm of multi-stage non cooperative positional game}

The optimal control of the own ship $u_{0}^{*}(t)$, which is equivalent to the optimal positional steering $u_{0}^{*}(p)$ for the current position $p(t)$, is determined from the condition:

$$
I=\min _{u_{0} \in U_{0}=\bigcap_{j=1}^{m} U_{0}^{j}}\left\{\max _{l_{j}^{m} \in U_{j}} \min _{u_{0}^{j} \in U_{0}^{j}\left(u_{j}\right)} \int_{t_{0}}^{t_{k}} u_{0}(t) d t\right\}=L_{0}^{*}\left(x_{0}\right)
$$

$L_{0}$ refers to the continuous function of the maneuvering goal of the own ship, describing the distance of the ship at the initial moment $t_{0}$ to the nearest turning point on the reference route of the voyage.

The optimal control of the own ship is calculated at each discrete stage of the ship's movement by applying the SIMPLEX method to solve the problem of the dual linear programming, assuming the relationship (4) as the goal function and the control constraints (2).

Using the function of $l p$ - linear programming from the Optimization Toolbox MATLAB, the positional multi-stage game non-cooperative maneuvering MNCPG program has been designed for the determination of the own ship safe trajectory in a collision situation.

\subsection{MCPG algorithm of multi-stage cooperative positional game}

Goal function (4) for cooperative positional game has the form:

$$
I=\min _{u_{0} \in U_{0}=\bigcap_{j=1}^{m} U_{0}^{j}}\left\{\min _{u_{j}^{m} \in U_{j}} \min _{u_{0}^{j} \in U_{0}^{j}\left(u_{j}\right)} \int_{t_{0}}^{t_{k}} u_{0}(t) d t\right\}=L_{0}^{*}\left(x_{0}\right)
$$




\subsection{MNCMG algorithm of multi-step non cooperative matrix game}

The matrix game $R=\left[r_{j}\left(v_{j}, v_{0}\right)\right]$ includes the value a collision risk $r_{j}$ with regard to the determined strategies $v_{0}$ of the own ship and those $v_{j}$ of the $j$-th encountered ships [6].

The value of the risk of the collision $r_{j}$ is defined as the reference of the current situation of the approach described by the parameters $D_{\min }^{j}$ and $T_{\operatorname{mir}}^{j}$, to the assumed assessment of the situation defined as safe and determined by the safe distance of approach $D_{s}$ and the safe time $T_{s}$ - which are necessary to execute a maneuvering to avoided collision with consideration actual distance $D_{j}$ between own ship and encountered $j$-th ship (see Figure 6).

$$
r_{j}=\left[a_{1}\left(\frac{D_{\min }^{j}}{D_{s}}\right)^{2}+a_{2}\left(\frac{T_{\min }^{j}}{T_{s}}\right)^{2}+a_{3}\left(\frac{D_{j}}{D_{s}}\right)^{2}\right]^{-\frac{1}{2}}
$$

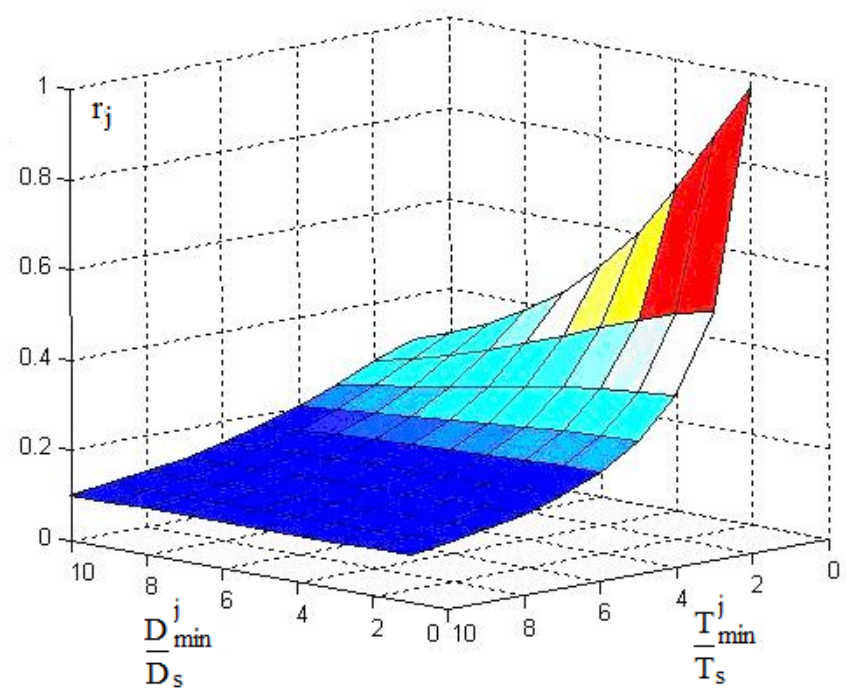

Figure 6: The space of ship collision risk.

As a result of using the following form for the control goal:

$$
\left(I_{0}^{j}\right)^{*}=\min _{v_{0}} \max _{v_{j}} r_{j}
$$

the probability matrix $P=\left[p_{j}\left(v_{j}, v_{0}\right)\right]$ of using particular pure strategies may be obtained. 
The solution for the control goal is the strategy of the highest probability:

$$
\left(u_{0}^{v_{0}}\right)^{*}=u_{o}^{v_{0}}\left\{\left[p_{j}\left(v_{j}, v_{0}\right)\right]_{\max }\right\}
$$

Using the function of $l p$ - linear programming from the Optimization Toolbox MATLAB, the matrix multi-step game maneuvering MNCMG program has been designed for the determination of the own ship safe trajectory in a collision situation.

\subsection{MCMG algorithm of multi-step non cooperative matrix game}

Goal function (7) for cooperative matrix game has the form:

$$
\left(I_{0}^{j}\right)^{*}=\min _{v_{0}} \min _{v_{j}} r_{j}
$$

\section{Computer simulation}

Computer simulation of MNCPG, MCPG, MNCMG and MCMG algorithms was carried out in Matlab/Simulink software on an example of the real navigational situation of passing $j=12$ encountered ships in the Kattegat Strait in restricted visibility, when $D_{s}=1 \mathrm{~nm}$ (nautical miles), (see Table 2 and Figures 7-11).

The situation was registered on board r/v HORYZONT II, a research and training vessel of the Gdynia Maritime University, on the radar screen of the ARPA anti-collision system Raytheon.

Table 2: Movement parameters of ships.

\begin{tabular}{|c|c|c|c|c|}
\hline $\mathbf{j}$ & $\mathbf{D}_{\mathbf{j}}$ & $\mathbf{N}_{\mathbf{j}}$ & $\mathbf{V}_{\mathbf{j}}$ & $\boldsymbol{\psi}_{\mathbf{j}}$ \\
\hline- & $\boldsymbol{n m}$ & $\boldsymbol{d e g}$ & $\boldsymbol{k n}$ & $\boldsymbol{d e g}$ \\
\hline 0 & - & - & 12 & 0 \\
\hline 1 & 11.8 & 15 & 9 & 206 \\
\hline 2 & 6.0 & 37 & 18 & 246 \\
\hline 3 & 7.8 & 330 & 12 & 135 \\
\hline 4 & 4.1 & 14 & 0 & 0 \\
\hline 5 & 6.1 & 359 & 6 & 33 \\
\hline 6 & 4.9 & 351 & 0 & 0 \\
\hline 7 & 5.0 & 270 & 8 & 350 \\
\hline 8 & 8.3 & 55 & 18 & 334 \\
\hline 9 & 6.4 & 72 & 15 & 0 \\
\hline 10 & 6.7 & 350 & 13 & 3 \\
\hline 11 & 7.5 & 29 & 0 & 0 \\
\hline 12 & 8.3 & 34 & 12 & 0 \\
\hline
\end{tabular}




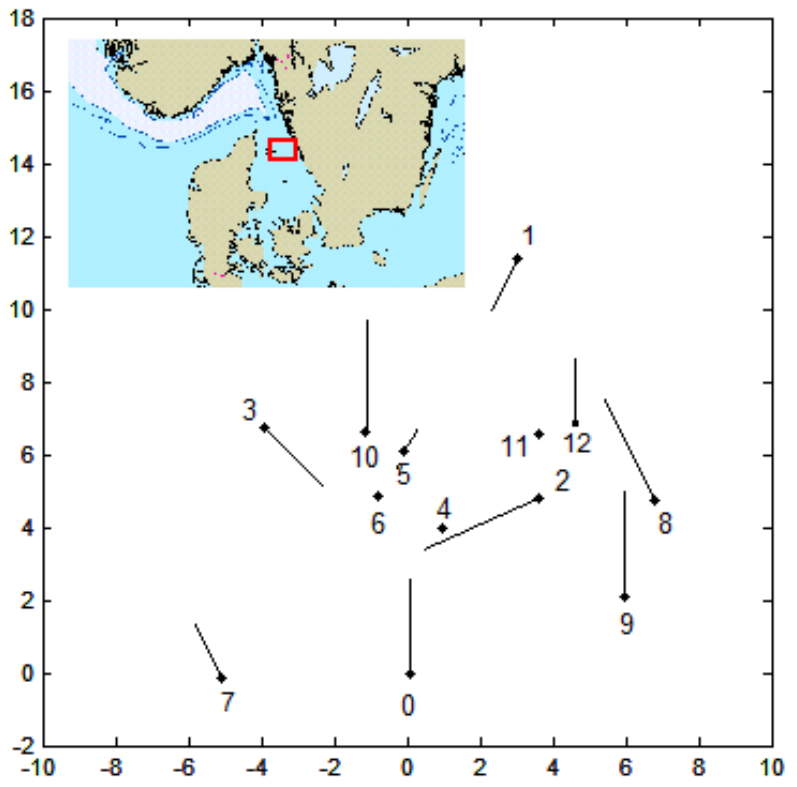

Figure 7: The 6 minute speed vectors of ships.

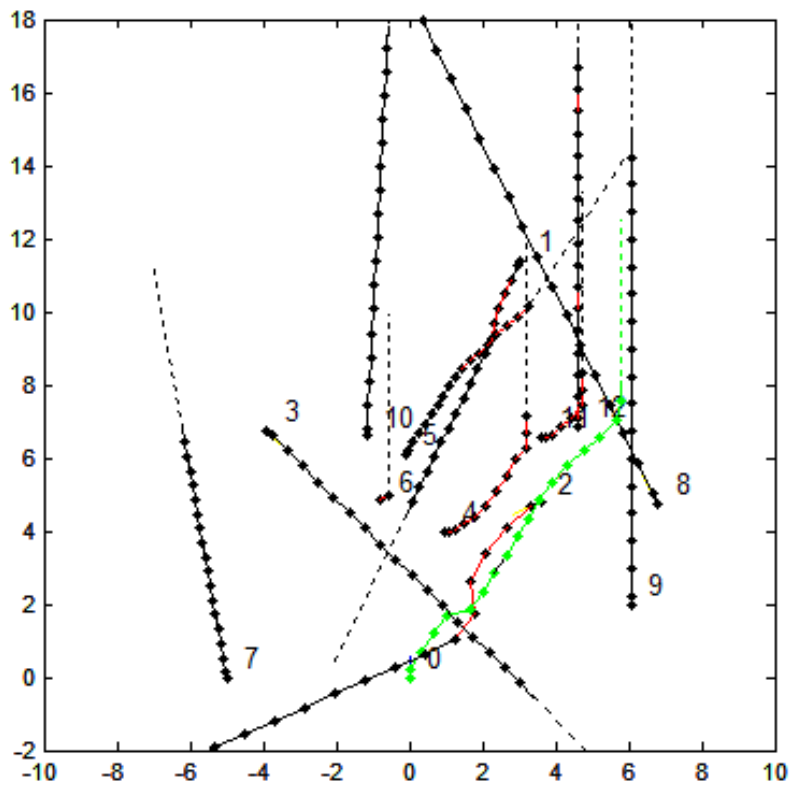

Figure 8: The safe trajectory of own ship for MNCPG algorithm, $\mathrm{d}(\mathrm{tk})=5.78 \mathrm{~nm}$. 


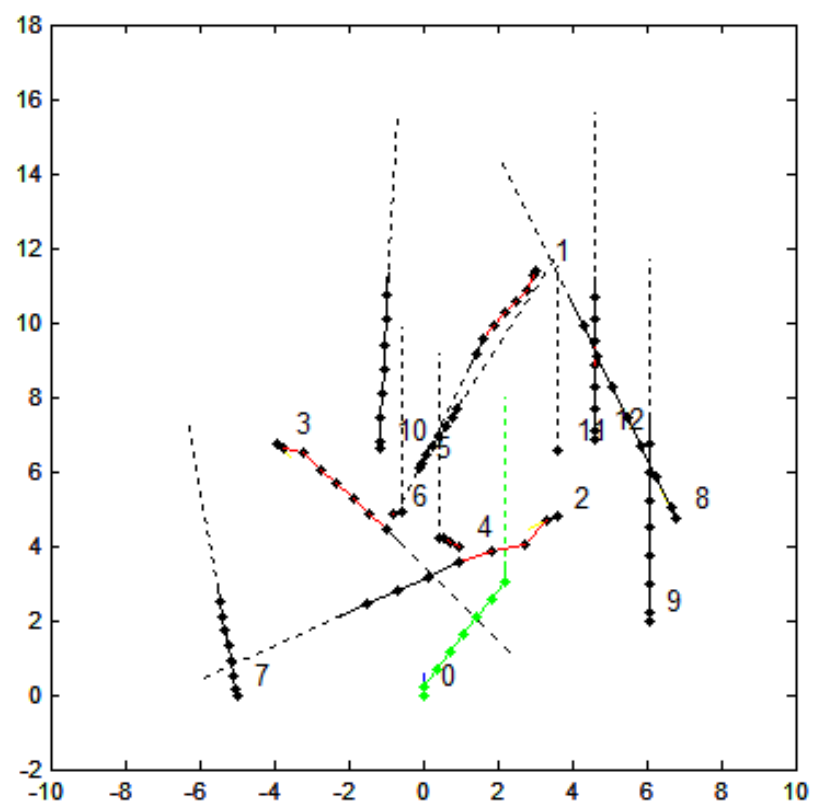

Figure 9: The safe trajectory of own ship for MCPG algorithm, $\mathrm{d}(\mathrm{tk})=2.21 \mathrm{~nm}$.

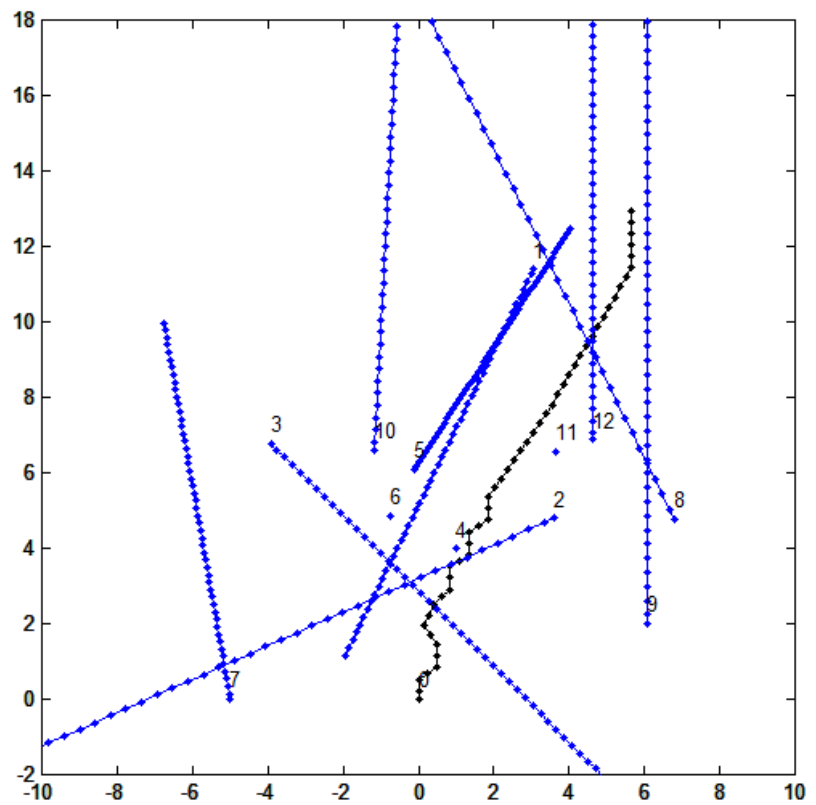

Figure 10: The safe trajectory of own ship for MNCMG algorithm, $\mathrm{d}(\mathrm{tk})=5.82 \mathrm{~nm}$. 


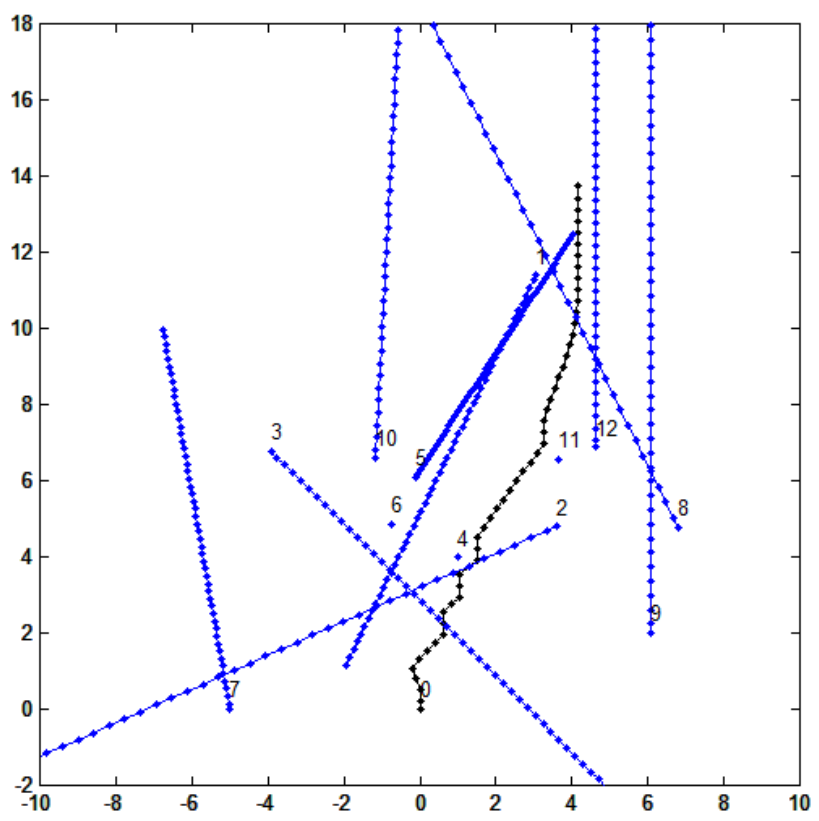

Figure 11: The safe trajectory of own ship for MCMG algorithm, $d\left(t_{k}\right)=4.31 \mathrm{~nm}$.

\section{Conclusions}

The control methods considered in this paper are, in a certain sense, formal models for the thinking processes of a navigating officer steering of own ships. The developed algorithms takes also into consideration the COLREGS Rules and the advance time of the manoeuvre approximating the ship's dynamic properties and evaluates the final deviation of the real trajectory from the reference value. These algorithms can be used for computer supporting of navigator safe maneuvering decision in a collision situations using information from ARPA anti-collision radar system.

The use these algorithms by the own ship does not depend on whether other ships use the same software or not. MNCPG, MCPG, MNCMG and MCMG game algorithms take into account changes of course and speed of other cooperating or not cooperating ships in accordance with the COLREGS Rules.

The essential influence to form of safe and optimal trajectory and value of deflection between game and reference trajectories has the number of admissible strategies of own ship and encountered ships.

It results from the performed simulation testing this algorithm is able to determine the correct game trajectory when the ship is not in a situation when she approaches too large number of the observed ships or the said ships are found at long distances among them. 


\section{References}

[1] Baba, N. and Jain, L.C., Computational intelligence in games: PhysicaVerlag, New York, 2001.

[2] Basar, T. and Olsder, G.J., Dynamic non-cooperative game theory: SIAM, Philadelphia, 1998.

[3] Bist, D.S., Safety and security at sea: Butter Heinemann, Oxford-New Delhi, 2000.

[4] Bole, A., Dineley, B. and Wall, A., Radar and ARPA manual: Elsevier, Amsterdam-Tokyo, 2006.

[5] Cahill, R.A., Collisions and their causes: The Nautical Institute, London, 2002.

[6] Cockcroft, A.N. and Lameijer, J.N.F., The collision avoidance rules: Elsevier, Amsterdam-Tokyo, 2006.

[7] Cymbal, N.N., Burmaka, I.A. and Tupikov, I.I., Elastic strategies of the passing ships: KP OGT, Odessa, 2007 (in Russian).

[8] Engwerda, J.C., LQ dynamic optimization and differential games: John Wiley and Sons, West Sussex, 2005.

[9] Gluver, H. and Olsen, D., Ship collision analysis: A.A. Balkema, Rotterdam-Brookfield, 1998.

[10] Hasegawa, K., Shigemori, Y. and Ichiyama, Y., Feasibility study on intelligent marine traffic system. In: Proc. of the Maritime Conference of Manoeuvring Crafts, Aalborg, 2000.

[11] Isaacs, R., Differential games: John Wiley \& Sons, New York, 1965.

[12] Lee, H.J. and Rhee, K.P., Development of collision avoidance system by using expert system and search algorithm. International Shipbuilding Progress, 48, 2001, pp. 197-212.

[13] Millington, I., Funge, J., Artificial intelligence for games: Elsevier, Amsterdam-Tokyo, 2009.

[14] Modarres, M., Risk analysis in engineering: Taylor \& Francis Group, Boca Raton, 2006.

[15] Nisan, N., Roughgarden, T., Tardos, E., Vazirani, V.V., Algorithmic game theory: Cambridge University Press, New York, 2007.

[16] Osborne, M.J., An introduction to game theory: Oxford University Press, New York, 2004.

[17] Zio, E., Computational methods for reliability and risk analysis. Series on Quality, Reliability and Engineering Statistics, 14, 2009, pp. 295-334. 